\title{
Charles d'Orléans, Le Livre d'Amis: Poésies à la cour de Blois (1440-1465)
}

\section{Paola Cifarelli}

\section{OpenEdition}

\section{Journals}

\section{Édition électronique}

URL : http://journals.openedition.org/studifrancesi/5538

DOI : 10.4000/studifrancesi.5538

ISSN : 2427-5856

\section{Éditeur}

Rosenberg \& Sellier

\section{Édition imprimée}

Date de publication : 1 septembre 2011

Pagination : 387

ISSN : 0039-2944

\section{Référence électronique}

Paola Cifarelli, «Charles d'Orléans, Le Livre d'Amis: Poésies à la cour de Blois (1440-1465) », Studi Francesi [En ligne], 164 (LV | II) | 2011, mis en ligne le 30 novembre 2015, consulté le 07 janvier 2021. URL

http://journals.openedition.org/studifrancesi/5538; DOI : https://doi.org/10.4000/studifrancesi.5538

Ce document a été généré automatiquement le 7 janvier 2021.

\section{$@ \odot \Theta \Theta$}

Studi Francesi è distribuita con Licenza Creative Commons Attribuzione - Non commerciale - Non opere derivate 4.0 Internazionale. 


\title{
Charles d'Orléans, Le Livre d'Amis: Poésies à la cour de Blois (1440-1465)
}

\author{
Paola Cifarelli
}

\section{RÉFÉRENCE}

CHARLES D'ORLÉANS, Le Livre d'Amis: Poésies à la cour de Blois (1440-1465). Édition bilingue.

Publication, traduction, présentation et notes par Virginie MINET-MAHY et Jean-Claude MÜHLETHALER, Paris, Champion, 2010 («Champion Classiques - Série 'Moyen Âge',

Éditions bilingues» 28), 752 pp.

1 Deux éminents spécialistes de la poésie aurélienne ont travaillé à ce beau volume, qui renferme le texte et la traduction en français moderne des poèmes post-carcéraux de Charles d'Orléans et des poètes qui fréquentaient la cour de Blois, transcrits dans le célèbre manuscrit Paris, BnF, fr. 25458. Longtemps considéré comme dominé par le hasard, qui aurait été à la base de l'activité de copie des textes par les scribes, ce codex a été l'objet d'études récentes qui ont permis de révolutionner cette perspective et de saisir son principe structurant dans la volonté de témoigner des débats poétiques qui ont animé la cour de Charles; véritable entreprise collective qui fait dialoguer les poèmes du prince poète avec ceux des autres membres du cercle culturel blésois, ce manuscrit partiellement autographe a pu être envisagé comme le fruit d'une écriture collaborative, «c'est-à-dire comme un processus dans lequel divers acteurs entrent en jeu pour l'élaboration du texte» (p. 27). À travers le présent ouvrage, le lecteur aura donc la possibilité de constater le bien-fondé des recherches de Jane Taylor (voir SF 159, p. 433), de Mary-Jo Arn (SF 162, pp. 535-536) et de tant d'autres critiques, qui ont mis en évidence la prééminence des concepts d'hybridité et de dialogisme dans la section du manuscrit copiée après le retour d'Angleterre. D'ailleurs, ces principes étaient déjà à la base de l'édition des Ballades et des Rondeaux procurée en 1999 par J.-C. Mühlethaler pour les Lettres Gothiques. 
2 Dans l'Introduction, J.-C.M. et V.M-M. retracent d'abord les étapes fondamentales de la vie de Charles d'Orléans, afin surtout de montrer pour quelles raisons la critique a souvent interprété sa production comme un 'cri du coeur', expression d'une subjectivité marquée par la mélancolie et le repli sur soi. Mais la perspective d'un jeu entre les différents moi poétiques, justifiée entre autres par l'importance que prennent la mise en scène lyrique et l'oralité dans plusieurs poèmes, s'avère plus fructueuse que la simple lumière autobiographique pour la compréhension du mécanisme qui régit le fonctionnement des différents textes à l'intérieur de ce liber amicorum.

3 Les notions de posture d'auteur et d'auto-figuration littéraire permettent donc de lire ce codex comme le fruit du rite social qu'est à l'époque l'écriture lyrique et de «reconsidérer le stéréotype du prince de mélancolie» (p. 27), remplacé plutôt par l'image d'un poète animé par la volonté d'établir un échange poétique et de jeter un regard souvent ironique sur les conventions de la poésie lyrique en jouant avec les registres, les types de Discours et l'ambiguïté de la parole. En effet, les textes sont souvent parcourus par une interaction intense et réalisent un jeu de réécriture qui permet de saisir une profonde intertextualité entre groupes de poèmes. C'est pourquoi les AA. recourent si souvent aux métaphores musicales de la polyphonie, de l'orchestration et de la variation pour décrire le fonctionnement du codex.

4 Afin de favoriser une lecture du Livre d'Amis qui tienne compte de ces principes, les AA. ont établi un Index des images et des registres thématiques, dans lequel figurent une centaine de catégories correspondant à des métaphores ou à des réseaux lexicaux (tels l'écriture et le livre, la chasse, le lieu clos, la maladie, l'économie ou la folie) qui reviennent dans plusieurs poèmes. Le chapitre de l'introduction intitulé Combinaison d'images et 'concours poétiques' fournit quelques exemples de la manière dont le lecteur pourra exploiter cet index, qui favorisera donc la lecture transversale et la possibilité d'établir des parallèles avec la production d'autres poètes ou de traiter un thème spécifique.

5 Pour ce qui est des poèmes de Charles d'Orléans transcrits et traduits dans ce volume, il s'agit des textes remontant à l'époque postérieure à la captivité anglaise; on ne trouvera donc pas les dizains constituant la Retenue d'amour, les ballades qui forment le Livre de joie, le Songe en Complainte et la Départie d'Amour, ainsi que quelques-unes des Ballades de divers propos et la plupart des chansons, des complaintes et des caroles. Les éditeurs ont également omis, pour des raisons de place, les ballades dites 'du concours de Blois'. Aux poèmes de Charles d'Orléans s'ajoutent, en s'intégrant dans la succession des textes, ceux que composèrent les autres auteurs: les serviteurs comme Jean Caillau, Fredet, Gilles des Ormes, Hugues le Voys et Benoît Damien, mais aussi les grands seigneurs (René d'Anjou, Jean d'Alençon, Jean de Lorraine, Charles de Nevers, Jean II de Bourbon, Marie de Clèves) et les poètes de passage tels Villon, Jean Robertet, George Chastelain, Olivier de la Marche, Jean Meschinot. En effet, les poèmes ont été édités de façon linéaire, suivant la succession du manuscrit. Une table des incipit permet d'établir la concordance avec l'édition de Pierre Champion, tandis que les notes portant surtout sur des aspects littéraires, historiques ou lexicaux - renvoient aussi systématiquement aux éditions de J.-C.M. (ballades et rondeaux) et de Sarah Spence (chansons). La traduction en français moderne, précise et soignée, rend accessibles les poèmes aussi à ceux qui n'ont pas une grande familiarité avec la langue du $\mathrm{Xv}^{\mathrm{e}}$ siècle, qui pourront se servir d'un texte absolument fiable. Un glossaire et surtout une riche bibliographie (incluant la liste des manuscrits et permettant de repérer toutes les 
études publiées dans les années récentes, qui manquent donc nécessairement dans les travaux antérieurs) complètent ce volume. 